\title{
An Academic GI Career: The World Is Your Oyster!
}

\author{
Neel Sharma ${ }^{1,2}$
}

Received: 19 July 2016/ Accepted: 16 August 2016/Published online: 20 August 2016

(C) Springer Science+Business Media New York 2016

Park and Laine [1] have provided great insight into academic pursuits during GI training. As a GI trainee coming to the end of my $\mathrm{PhD}$, I would like to add one additional dimension. As a UK-born doctor, my colleagues remained in the UK to undertake research training. However, I made the decision to go abroad, specifically Singapore, to complete my research pursuits. The explanation was simple. From a GI perspective I recognized as Westerners, we have a lot to learn from our Asian colleagues. We can recognize their vast ability in endoscopy with innovations in image enhancement and robotics originating in Asia. Yet we often fail to sometimes comprehend their abilities. They often do not follow Western guidance and while we produce guidelines upon guidelines, the outcomes in the East in many cases often overtake ours.

My research focus was on esophageal and gastric pathology and my mentor taught me the importance of simple lesion recognition. While I was eager to grab the scope, the focus initially remained simply on recognizing pathology, be it with white light, NBI or confocal-based tools. At the time, I questioned how this would benefit my training. But coming to the end I can recognize the value of this approach. I learnt focus and dedication, something that is most likely an element of culture. And it works.
Focusing on astute lesion recognition is often a function of focus as opposed to anything else.

My stint in Singapore allowed me to attend Asian-based conferences across Japan and Korea and learn the approaches in this part of the world and their thinking direction. Again often the reverse of the West with still optimum patient outcomes.

In life, we often hone in on particular areas. For me, it was London. The research elements at the time, however, were not of much interest. And I was concerned about undertaking a project simply for the London tag as opposed to anything else. My recommendations to readers out there-the world is your oyster!

\section{Compliance with ethical standards}

Conflict of interest None.

\section{Reference}

1. Park S, Laine L. Pursuing a clinical academic career during gastroenterology fellowship. Dig Dis Sci. 2016;61:2162. doi:10. 1007/s10620-016-4196-0.

Neel Sharma

sharma_neel@outlook.com

1 NUH Singapore, 1E Kent Ridge Road, Singapore 119228, Singapore

2 Harvard Macy Institute, Boston, MA, USA 